\title{
Utility of PD-L1 immunohistochemistry assays for predicting PD-1/PD-L1 inhibitor response
}

\author{
Laurence P. Diggs and Eddy C. Hsueh ${ }^{*}$
}

\begin{abstract}
We have seen a notable increase in the application of PD-1/PD-L1 inhibitors for the treatment of several solid and hematogenous malignancies including metastatic melanoma, non-small-cell lung cancer and lymphoma to name a few. The need for biomarkers for identification of a suitable patient population for this type of therapy is now pressing. While specific biomarker assays have been developed for these checkpoint inhibitors based on their respective epitopes, the available studies suggested the clinical utility of these biomarker assays is for response stratification and not patient selection. Further improvement in assay development is needed to utilize this type of assay in identification of ideal patient population for this therapy.
\end{abstract}

Keywords: Metastatic melanoma, Non-Small-Cell Lung Cancer, PD-1/PD-L1 inhibitors, PD-L1 immunohistochemistry assays

\section{Introduction}

Immune modulation therapies have seen an impressive growth over the last decade [1]. Recently, inhibitors of programmed cell-death receptor (PD-1) and its associated ligand (PD-L1) have gained significant attention from the oncology community. PD-L1, typically expressed on the surface of healthy cells, binds PD-1 on primed cytotoxic T cells thereby inhibiting cell-mediated attack [1-3]. Multiple studies reported worse outcomes in tumors expressing PD-L1 [2, 3]. Purportedly, the expression of this ligand on tumor cells confers protection against immunemediated attacks on tumor cells and may account for their particularly malignant potential. Anti-PD-L1 (or anti-PD1) monoclonal antibodies inhibit PD-L1 binding to PD-1 and allow $\mathrm{T}$ cell activity at this immune checkpoint. Several clinical trials using these antibodies for the treatment of malignancies such as melanoma, non-small-cell lung cancer (NSCLC), head and neck cancer, renal cell cancer, urothelial cancer and lymphoma have shown great promise in prolonging survival [4-10].

However, not all patients respond to PD-1/PD-L1 inhibitors. Thus, predicting the likelihood of response to

\footnotetext{
* Correspondence: hsuehec@slu.edu

Division of General Surgery, Department of Surgery, Saint Louis University, 3635 Vista at Grand Blvd., St. Louis, MO 63110, USA
}

treatment would aid in appropriate patient selection for these drugs. Immunohistochemistry (IHC) biomarker assays for respective PD-1/PD-L1 inhibitors were designed to screen for the presence of specific PD-1/PD-L1 epitopes as well as to estimate the percentage of $\mathrm{T}$ cells or tumor cells expressing this receptor or ligand. At this time, 4. FDA-approved IHC biomarker assays have been designed [10]. Their ability to consistently and reproducibly quantify proportion of cells expressing PD-L1 has been evaluated in prospective trials. Given the inherent heterogeneity of gene expression between individual tumors and among tumor cells within the same tumor nodules, there are concerns that any single assay using a fixed percentage of PD-L1 positive tumor cells could accurately determine the appropriate patients for treatment $[11,12]$. This is reflected in the finding that PD-1/ PD-L1 inhibitors appear to have activity in a subset of individuals who do not meet the IHC bioassay cutoff. Furthermore, recent studies suggested that several additional factors could be involved in the response to anti-PD-1/PD-L1 antibodies.

\section{Current PD-1 \& PD-L1 inhibitors}

Among the first generation of these drugs, Pembrolizumab (an anti PD-1 antibody) was approved for treatment 
of NSCLC [13-16] and melanoma [17-20] in 2014. Pembrolizumab has also recently been approved for use in advanced head and neck squamous cell carcinoma (HNSCC) [21, 22]. Nivolumab (an anti PD-1 antibody) was approved for melanoma in 2014 [23-28] NSCLC in 2015 [29-32] and renal cell carcinoma in 2015 [33, 34]. Pembrolizumab and Nivolumab have been demonstrated to improve overall and progression free survival in the above-mentioned tumors. Atezolizumab (an anti PD-L1 antibody) has received FDA designated breakthrough drug status for two malignancies. Clinical trials are currently underway for both metastatic NSCLC [35-37] and for urothelial carcinoma [38]. Durvalumab (an antiPD-L1 antibody) is also being evaluated in clinical trials for the treatment of NSCLC (phase III) [39] and bladder cancer (phase III) [40, 41]. Pidilizumab (an anti PD-1 antibody) is currently being tested in the treatment of large B cell lymphoma (Phase II completed) [42]. Finally, Avelumab (an anti PD-L1 antibody) is currently being tested in patients with Merkel cell carcinoma (Phase II) [43] and NSCLC (Phase III) [44].

\section{Current PD-1/PD-L1 bioassays}

Several studies examining the usefulness of PD-L1 IHC assays have demonstrated a direct correlation of response rate to PD-L1 expression level. The distinction between a companion assay and a complementary assay should be underlined here. A companion assay is one that is considered to be essential to the use of its corresponding drug. Pembrolizumab is FDA approved only when used in conjunction with the Dako 22C3. Conversely, the other bioassays are considered complementary in that their use is recommended in order to optimize appropriate patient selection but is not considered mandatory for the use of its associated drug [45]. The cutoff values for these assays vary from as low as $1 \%$ to as high as $50 \%$. To allow for comparison, sensitivity (SENS) and specificity (SPEC) of the bioassay for a given malignancy were calculated based on the reported objective response rate in individuals who were considered to have PD-L1 positive tumors (ORR+) and that of the individuals who were considered to have PD-L1 negative tumors (ORR-). Sensitivity was calculated as a ratio of true positives (ORR + ) to the sum of true positives (ORR+) and False Negatives (ORR-). Specificity was calculated as a ratio of true negatives (1-ORR-) to the sum of true negatives (1-ORR-) and false positives (1-ORR+).

Pembrolizumab is currently approved for the treatment of NSCLC, advanced HNSCC and advanced melanoma. Its companion IHC biomarker assay, Dako $22 \mathrm{C} 3$, is used to detect PD-L1 in all three types of malignancies. It is the only assay that has FDA companion status [45]. This exceptional status is due to the assays reliability when testing for PD-L1 positivity making it an essential tool when assessing which candidates are appropriate for treatment with Pembrolizumab. The Dako 22C3 PD-L1 positivity cutoff is $1 \%$ for melanoma. The average ORR+ is $39 \%$ for PD-L1 positive tumors and the average ORR- is 10\% for PD-L1 negative tumors. These estimates are based on the findings from Daud et al. [19] who graded PD-L1 positivity and negativity based on the MEL score. Using a $1 \%$ expression as a cutoff, MEL scores of 0 and 1 were considered negative whereas MEL scores of 2,3,4 and 5 were considered positive. The ORR- and ORR+ were weighted averages of MEL 0 and 1 and MEL $2-5$ respectively. The associated SENS and SPEC for this bioassay are 80 and 60\%, respectively. The cutoff for HNSCC PD-L1 positivity is also $1 \%$. The ORR+ and ORR- are $22 \%$ and $4 \%$, respectively [21, 22]. SENS is $85 \%$ and SPEC is $55 \%$. For NSCLC, the Dako 22C3 PD-L1 positivity cutoff is $50 \%$. ORR+ and ORR- are 41 and 13\%, respectively [13-15]. The SENS is $76 \%$ and the SPEC is $60 \%$ (Table 1 ).

Nivolumab is currently approved for the treatment of squamous and non-squamous NSCLC, advanced RCC and advanced melanoma. Its companion PD-L1 IHC biomarker assay, Dako $28-8$, is only used in tumor tissue from NSCLC and melanoma [46]. In the case of RCC, the PD-L1 expression detected on Dako 28-8 was not predictive of response to Nivolumab [33, 34]. Nivolumab is considered second line therapy for RCC regardless of PD-L1 status. For melanoma, the Dako 28-8 PDL1 positivity cutoff is $5 \%$. The ORR+ was $57 \%$ and the ORR- was $41 \%$ and the associated SENS and SPEC are 58 and $49 \%$. An interesting set of findings was brought about when Nivolumab was combined with Ipilimumab, an anti- CTLA4 antibody. The ORR+ and ORR- are 72 and 55\%, respectively and the associated SENS and SPEC for this bioassay are 57 and $54 \%$, respectively [25, $27,28]$. The Dako $28-8$ cutoff for NSCLC is $1 \%$. For non-squamous NSCLC, the ORR+ and ORR- are 19 and $9 \%$, respectively [32]. SENS is $68 \%$ and SPEC is $53 \%$. For squamous NSCLC, there was no significant difference between ORR+ and ORR- which could be estimated at approximately $20 \%$ [30,31]. The SENS and SPEC could therefore not be calculated (Table 1).

Durvalumab is currently approved for the treatment of NSCLC and bladder cancer. Its companion IHC biomarker assay is Roche Ventana SP263 [47]. The SP263 PD-L1 positivity cutoff is $25 \%$ for NSCLC. The ORR is $27 \%$ for PD-L1 positive tumors and $5 \%$ for PD-L1 negative tumors [39]. The associated SENS and SPEC are 84 and $78 \%$, respectively. A recent study compared Durvalumab alone to combination therapy with Durvalumab and Tremelimumab (an anti CTLA-4 antibody). The ORR+ and ORR- were 22.5 and $29 \%$ respectively indicated that the ORR appeared to be negatively affected by higher PD-L1 expression. The SENS and SPEC were 36 and 48\%. The SP263 cutoff for bladder cancer is also 
Table 1 Biomarker assays for anti-PD-1/PD-L1 drugs and associated outcomes

\begin{tabular}{|c|c|c|c|c|c|c|c|}
\hline Bioassay & Drug & Disease Target & Cut Off ${ }^{b}$ & $\mathrm{ORR}^{c}{ }^{\mathrm{c}}$ & ORR- $^{d}$ & SENS $^{\mathrm{e}}$ & SPEC $^{f}$ \\
\hline Roche Ventana SP263 & Durvalumab & $\mathrm{NSCLC}^{\mathrm{a}}$ & $25 \%$ & $27 \%$ & $5 \%$ & $84 \%$ & $78 \%$ \\
\hline Roche Ventana SP263 & Durvalumab + Tremelimumab & NSCLC & $25 \%$ & $22.5 \%$ & $29 \%$ & $36 \%$ & $48 \%$ \\
\hline Roche Ventana SP263 & Durvalumab & Bladder Cancer & $25 \%$ & $46 \%$ & $0 \%$ & $100 \%$ & $65 \%$ \\
\hline Roche Ventana SP142 & Atezolizumab & Metastatic NSCLC & $50 \%$ & $45 \%$ & $14 \%$ & $76 \%$ & $61 \%$ \\
\hline Roche Ventana SP142 & Atezolizumab & Urothelial Carcinoma & $1 \%$ & $27 \%$ & $13 \%$ & NA & NA \\
\hline Dako 22C3 & Pembrolizumab & NSCLC & $50 \%$ & $41 \%$ & $13 \%$ & $76 \%$ & $60 \%$ \\
\hline Dako 22C3 & Pembrolizumab & HNSCC & $1 \%$ & $22 \%$ & $4 \%$ & $85 \%$ & $55 \%$ \\
\hline Dako $22 \mathrm{C} 3^{9}$ & Pembrolizumab & Melanoma & $1 \%$ & $39 \%$ & $10 \%$ & $80 \%$ & $60 \%$ \\
\hline Dako 28-8 & Nivolumab & Non-Squamous NSCLC & $1 \%$ & $19 \%$ & $9 \%$ & $68 \%$ & $53 \%$ \\
\hline Dako 28-8 & Nivolumab & Squamous NSCLC & $5 \%$ & $20 \%$ & $20 \%$ & NA & NA \\
\hline Dako 28-8 & Nivolumab & Melanoma & $5 \%$ & $57 \%$ & $41 \%$ & $58 \%$ & $49 \%$ \\
\hline Dako 28-8 & Nivolumab + Ibilimumab & Melanoma & $5 \%$ & $72 \%$ & $55 \%$ & $57 \%$ & $54 \%$ \\
\hline
\end{tabular}

${ }^{a}$ NSCLC: Non-Small-Cell Lung Cancer $-{ }^{b}$ Cut Off: Proportion of tumor cells expressing PD-L1 below which tumor is considered PD-L1 negative. - ${ }^{\mathrm{C} O R R+}$ Objective Response Rate in PD-L1 positive tumors. - ${ }^{\mathrm{d}}$ ORR-: Objective Response Rate in PD-L1 negative tumors. - ${ }^{\mathrm{e}}$ Sensitivity of bioassay for predicting response

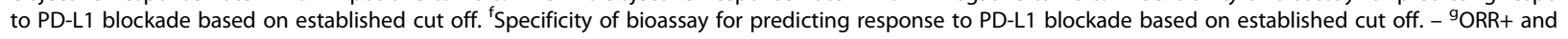
ORR- based on weighted average of corresponding MEL scores

$25 \%$. The ORR+ and ORR- are 46 and $0 \%$, respectively $[40,41]$ with an associated SENS of $100 \%$ and SPEC of 65\% (Table 1).

Atezolizumab is currently approved for treatment of metastatic NSCLC and urothelial cancer [35]. Its companion IHC biomarker assay is Roche Ventana SP142. The SP142 PD-L1 positivity cutoff is $50 \%$ for NSCLC. ORR+ is $45 \%$ and ORR- is $14 \%$ [36, 37] The associated SENS and SPEC are 76 and 61\%, respectively. The cutoff for urothelial cancer is $1 \%$. The ORR+ and ORR- are $27 \%$ and $15 \%$, respectively [38]. However, in this study, the ORR- included both patients with IHC staining $<1 \%$ and patients with IHC staining between 1 and 5\%. Therefore, the SENS and SPEC for SP142 in urothelial cancer could not be calculated (Table 1).

In general, the average specificity for these assays is $58 \%$. Thus, approximately $42 \%$ of patients who are not likely to respond to treatment are considered PD-L1+. Furthermore, the average overall sensitivity of these assays with their respective cutoff levels is $72 \%$; suggesting an average of $28 \%$ of patients who are considered PD-L1 negative may benefit from this type of treatment. The estimates are based on the figures seen in table.

\section{Factors influencing PD-L1 expression}

The mechanism of PD-L1 expression is complex. Several factors appear to influence both PD-L1 expression and response to treatment [48-52]. BRAF and MEK mutations contribute to dysfunction of the Ras-Raf-MEKERK Map kinase mutations that are present in greater than $90 \%$ of melanomas. Specific BRAF mutations when pretreated with Dabrafenib have been associated with reduced response to $\mathrm{PD}-1 / \mathrm{PD}-\mathrm{L} 1$ inhibition in melanoma [53-55]. However, when Dabrafenib was combined with MEK suppressor Tremelimumab, an improved response to PD-L1 inhibition was noted [55, 56]. Similarly, blockade of mutated BRAF and MEK was associated with improved response to PD-1/PD-L1 inhibition in NSCLC. Another interesting relationship is the one between mutations in EGFR and EML4-ALK and the expression of PD-L1. Recent studies indicate that EGFR mutations and rearrangements in EML4-ALK are associated with up regulation of PD-L1 synthesis and expression in NSCLC [57-59]. This was further established when patients with these mutations were treated with tyrosine kinase inhibitors and exhibited in lower overall response to PD-L1 blockade [60]. The presence of KRAS in the tumor also appears to be associated with increased expression of PD-L1 [60]. In a case report, KRAS pretreatment is reported to have increased response to Nivolumab in a patient who had not responded to several other treatment courses [61]. In addition, PD-L1 expression can increase due to local pro-inflammatory factors. Cigarette smoking in patients with NSCLC appears to increase the number of lymphocytes present as well as the overall proportion of PD-L1 present [62]. Platinum based chemotherapy [63] also appears to affect the tumor environment in a similar way to cigarette smoke. Additional studies have attributed tumor resistance to immunotherapies to immunosuppressive events occurring in the tumor microenvironment. Several of the mechanisms have been studied in clinical samples and validated in mouse models. The most important may be extrinsic suppression of CD8+ effector cells by CD $4+\mathrm{CD} 25+$ FoxP3+ regulatory T cells (Tregs) $[64,65]$. The metabolic deregulation via tryptophan catabolism by indoleamine-2,3-dioxygenase (IDO) may also play a role [66]. With multiple intrinsic and 
extrinsic factors influencing PD-L1 expression, PD-L1 expression may vary over time. Since tumor cells can exert an adaptive immune response over time, tumor tissue may express little PD-L1 at the moment of tissue sampling for IHC staining but expression may increase considerably at later time point in the disease course $[52,67,68]$.

\section{Conclusion}

Modification of specific checkpoints in anti-tumor immune response has resulted in significant improvement for the treatment of various malignancies. The relationship between tumor expression of PD-L1 and patient outcome has been established. However, the currently available IHC biomarker assays could not provide clinically meaningful identification of responders and nonresponders $[11,12,67,68]$. The sensitivity and specificity of the IHC assays are generally poor. The stringent application of the results of these assays would exclude up to $28 \%$ of individuals who may benefit from treatment and include up to $42 \%$ of patients who may not benefit.

Several tumor and patient characteristics appear to influence response to PD-1/PD-L1 inhibitor and should be considered when selecting patients for this treatment. Providing several tissue samples and obtaining tissue samples at different time intervals may allow for more accurate determination of appropriate patient for treatment.

A direct comparison of the clinical utility of these diagnostic assays for lung cancer was recently completed. In the Blueprint PD-L1 IHC Assay Comparison Project, the Pathology Committee of the International Association for the Study of Lung Cancer joined efforts with 6 of the commercial stakeholders (Astra Zeneca, Bristol Myers Squibb, Dako, Merck Sharpe Dohme, Roche/Genentech Pharmaceuticals, and Roche Ventana Diagnostics) to compare these tests. 3 of the 4 assays showed similar results but the SP142 demonstrated significantly less expression [72]. The interchangeability of the current assays is likely to be a challenge [69-71]. One promising strategy is the study of mRNA via in situ hybridization aimed at providing useful data for predicting success of these drugs on their targets [73].

\section{Acknowledgements}

Not applicable.

\section{Funding}

ECH receives research support from Saint Louis University Cancer Center.

\section{Availability of data and materials}

Not applicable.

\section{Authors' contributions}

LPD prepared the majority of the manuscript. ECH performed the final revision and was a major contributor in preparation of the manuscript. All authors read and approved the final manuscript.

\section{Competing interests}

$\mathrm{ECH}$ is on the Speaker Bureau of Amgen, Inc, and receives honoria for speaking engagement.

Consent for publication

Not applicable.

Ethics approval and consent to participate

Not applicable.

\section{Publisher's Note}

Springer Nature remains neutral with regard to jurisdictional claims in published maps and institutional affiliations.

Received: 6 January 2017 Accepted: 7 March 2017

Published online: 15 March 2017

References

1. Tumeh PC, Harview CL, Yearley JH, Shintaku IP, Taylor EJ, Robert L, et al. PD-1 blockade induces responses by inhibiting adaptive immune resistance. Nature. 2014;515(7528):568-71. doi:10.1038/nature13954.

2. Gatalica Z, Snyder C, Maney T, Ghazalpour A, Holterman DA, Xiao N, et al. Programmed cell death 1 (PD-1) and its ligand (PD-L1) in common cancers and their correlation with molecular cancer type. Cancer Epidemiol Biomarkers Prev. 2014;23(12):2965-70.

3. Patel SP, Kurzrock R. PD-L1 expression as a predictive biomarker in cancer immunotherapy. Mol Cancer Ther. 2015;14(4):847-56.

4. Massi D, Brusa D, Merelli B, Ciano M, Audrito V, Serra S, et al. PD-L1 marks a subset of melanomas with a shorter overall survival and distinct genetic and morphological characteristics. Ann Oncol. 2014;25(12):2433-42.

5. Wang W, Lau R, Yu D, Zhu W, Korman A, Weber J. PD1 blockade reverses the suppression of melanoma antigen-specific CTL by CD4+ CD25(Hi) regulatory T cells. Int Immunol. 2009;21(9):1065-77.

6. Daud Al, Loo K, Pauli ML, Sanchez-Rodriguez R, Sandoval PM, Taravati K, et al. Tumor immune profiling predicts response to anti-PD-1 therapy in human melanoma. J Clin Invest. 2016;126(9):3447-52. doi:10.1172/JCl87324.

7. Callea M, Albiges L, Gupta M, Cheng SC, Genega EM, Fay AP, et al. PD-L1 expression in primary clear cell renal cell carcinomas (cCRCCs) and their metastases. J Clin Oncol. 2014:32:5s.

8. Brahmer JR. Harnessing the immune system for the treatment of nonsmall- cell lung cancer. J Clin Oncol. 2013;31(8):1021-8.

9. Cancer Genome Atlas Network. Comprehensive genomic characterization of head and neck squamous cell carcinomas. Nature. 2015;517(7536):576-82.

10. Ma W, Gilligan BM, Yuan J, Li T. Current status and perspectives in translational biomarker research for PD-1/PD-L1 immune checkpoint blockade therapy. J Hematol Oncol. 2016;9:47. doi:10.1186/s13045-016-0277-y.

11. Kerr KM, Hirsch FR. Programmed death ligand-1 immunohistochemistry friend or foe? Arch Pathol Lab Med. 2016;140:326-31.

12. Kerr KM, Tsao MS, Nicholson AG, Yatabe Y, Wistuba II, Hirsch FR, et al. Programmed death-ligand 1 immunohistochemistry in lung cancer: in what state is this art? J Thorac Oncol. 2015;10(7):985-9.

13. Reck M, Rodríguez-Abreu D, Robinson AG, Hui R, Csőszi T, Fülöp A, et al. Pembrolizumab versus chemotherapy for PD-L1-positive non-small-cell lung cancer. N Engl J Med. 2016;375:1823-33. doi:10.1056/NEJMoa1606774. November 10, 2016

14. Garon EB, Rizvi NA, Hui R, Leighl N, Balmanoukian AS, Eder JP, et al. Pembrolizumab for the treatment of non-small-cell lung cancer. N Engl J Med. 2015;372(21):2018-28.

15. Herbst RS, Baas P, Kim DW, Felip E, Pérez-Gracia JL, Han JY, et al. Pembrolizumab versus docetaxel for previously treated, PD-L1-positive, advanced non-small-cell lung cancer (KEYNOTE-010): a randomised controlled trial. The Lancet. 2015;387(10027):1540-50.

16. Garon EB, Gandhi L, Rizvi N, Hui R, Balmanoukian AS, Patnaik A, et al. Antitumor activity of pembrolizumab (pembro; mk-3475) and correlation with programmed death ligand 1 (pd-I1) expression in a pooled analysis of patients (pts) with advanced non-small cell lung carcinoma (NSCLC). Ann Oncol. 2014;25 suppl 4:LBA43.

17. Ribas A, et al. Association of pembrolizumab with tumor response and survival among patients with advanced melanoma. JAMA. 2016;315:1600.

18. Robert C, Schachter J, Long GV, Arance A, Grob JJ, Mortier L. Pembrolizumab versus ipilimumab in advanced melanoma. N Engl J Med. 2015;372:2521-32. 
19. Daud Al, Wolchok JD, Robert C, Hwu WJ, Weber JS, Ribas A, et al. Programmed death-ligand 1 expression and response to the antiprogrammed death 1 antibody pembrolizumab in melanoma. J Clin Oncol. 2016;34(34):4102-9. Epub 2016 Oct 31.

20. Ribas A, Puzanov I, Dummer R, Schadendorf D, Hamid O, Robert C, et al. Pembrolizumab versus investigator-choice chemotherapy for ipilimumabrefractory melanoma (KEYNOTE-002): a randomised, controlled, phase 2 trial. Lancet Oncol. 2015;16(8):908-18.

21. Chow LQ, Haddad R, Gupta S, Mahipal A, Mehra R, Tahara M, et al. Antitumor activity of pembrolizumab in biomarker-unselected patients with recurrent and/or metastatic head and neck squamous cell carcinoma: results from the phase lb KEYNOTE-012 expansion. Cohort J Clin Oncol. 2016:32:3838-45.

22. Seiwert TY, Burtness B, Mehra R, Weiss J, Berger R, Eder JP, et al. Safety and clinical activity of pembrolizumab for treatment of recurrent or metastatic squamous cell carcinoma of the head and neck (KEYNOTE-012): an openlabel, multicentre, phase 1b trial. Lancet Oncol. 2016;17(7):956-65.

23. Topalian S, Sznol M, McDermott, Kluger HM, Carvajal RD, Sharfman WH, et al. Survival, durable tumor remission, and longterm safety in patients with advanced melanoma receiving nivolumab. J Clin Oncol. 2014;32(10):1020-30.

24. Weber JS, D'Angelo SP, Minor D, Hodi FS, Gutzmer R, Neyns B, et al. Nivolumab versus chemotherapy in patients with advanced melanoma who progressed after anti-CTLA-4 treatment (CheckMate 037): a randomised, controlled, open-label, phase 3 trial. Lancet Oncol. 2015;16(4):375-84.

25. Larkin J, Hodi FS, Wolchok JD. Combined Nivolumab and Ipilimumab or Monotherapy in Untreated Melanoma. N Engl J Med. 2015;373:23-34.

26. Robert C, Long GV, Brady B, Dutriaux C, Maio M, Mortier L, et al. Nivolumab in previously untreated melanoma without BRAF mutation. N Engl J Med. 2015;372(4):320-30.

27. Postow MA, Chesney J, Pavlick AC, Robert C, Grossmann K, McDermott D, et al. Nivolumab and ipilimumab versus ipilimumab in untreated melanoma. N Engl J Med. 2015;372:2006-17.

28. Hodi FS, Chesney J, Pavlick AC, Robert C, Grossmann KF, McDermott DF, et al. Combined nivolumab and ipilimumab versus ipilimumab alone in patients with advanced melanoma: 2-year overall survival outcomes in a multicentre, randomised, controlled, phase 2 trial. Lancet Oncol. 2016;17(11):1558-68

29. Gettinger SN, Horn L, Gandhi L, Spigel DR, Antonia SJ, Rizvi NA, et al. Overall survival and long-term safety of nivolumab (anti-programmed death 1 antibody, BMS-936558, ONO-4538) in patients with previously treated advanced non-small-cell lung cancer. J Clin Oncol. 2015;33(18):2004-12.

30. Brahmer J, Reckamp KL, Baas P, Crinò L, Eberhardt WE, Poddubskaya E, et al. Nivolumab versus docetaxel in advanced squamous-cell non-small-cell lung cancer. N Engl J Med. 2015;373(2):123-35.

31. Rizvi NA, Mazières J, Planchard D, Stinchcombe TE, Dy GK, Antonia SJ, et al. Activity and safety of nivolumab, an anti-PD-1 immune checkpoint inhibitor, for patients with advanced, refractory squamous non-small-cell lung cancer (CheckMate 063): a phase 2, single-arm trial. Lancet Oncol. 2015;16(3):257-65.

32. Borghaei H, Paz-Ares L, Horn L, Spigel DR, Steins M, Ready NE, et al. Nivolumab versus docetaxel in advanced non-squamous non-small-cell lung cancer. N Engl J Med. 2015;373(17):1627-39.

33. McDermott DF, Drake CG, Sznol M, Choueiri TK, Powderly JD, Smith DC, et al. Survival, durable response, and long-term safety in patients with previously treated advanced renal cell carcinoma receiving nivolumab. J Clin Oncol. 2015;33(18):2013-20.

34. Nivolumab combined with ipilimumab versus sunitinib in previously untreated advanced or metastatic renal cell carcinoma (CheckMate 214) ClinicalTrials.gov Identifier: NCT02231749.

35. Herbst RS, Soria JC, Kowanetz M, Fine GD, Hamid O, Gordon MS, et al. Predictive correlates of response to the anti-PD-L1 antibody MPDL3280A in cancer patients. Nature. 2014;515(7528):563-7.

36. Fehrenbacher L, Spira A, Ballinger M, Kowanetz M, Vansteenkiste J, Mazieres $J$, et al. Atezolizumab versus docetaxel for patients with previously treated non-small-cell lung cancer (POPLAR): a multicentre, open-label, phase 2 randomised controlled trial. Lancet. 2016;387(10030):1837-46.

37. Herbst RS, De Marinis F, Jassem J, Lam S, Mocci S, Sandler A, et al. PS01.56: IMpower110: phase III trial comparing $1 \mathrm{~L}$ atezolizumab with chemotherapy in PD-L1-selected chemotherapy-naive NSCLC patients. J Thorac Oncol. 2016;11(11):S304-5.

38. Rosenberg JE, Hoffman-Censits J, Powles T, van der Heijden MS, Balar AV, Necchi A, et al. Atezolizumab in patients with locally advanced and metastatic urothelial carcinoma who have progressed following treatment with platinum-based chemotherapy: a single-arm, multicentre, phase 2 trial. Lancet. 2016;387:1909-20.

39. Planchard D, Yokoi T, McCleod MJ, Fischer JR, Kim YC, Ballas M, et al. A phase III study of durvalumab (MEDI4736) with or without tremelimumab for previously treated patients with advanced NSCLC: rationale and protocol design of the ARCTIC study. Clin Lung Cancer. 2016;17(3):232.

40. Brower V. Anti-PD-L1 inhibitor Durvalumab in bladder cancer. Lancet Oncol. 2016;17(7):e275

41. Massard C, Gordon MS, Sharma S, Rafii S, Wainberg ZA, Luke J, et al. Safety and efficacy of durvalumab (MEDI4736), an anti-programmed cell death ligand-1 immune checkpoint inhibitor, in patients with advanced urothelial bladder cancer. J Clin Oncol. 2016:34:26. 3119-3125.

42. Bryan LJ, Gordon LI. Pidilizumab in the treatment of diffuse large B-cell lymphoma. Expert Opin Biol Ther. 2014;14(9):1361-8.

43. Sidaway P. Skin cancer: Avelumab effective against Merkel-cell carcinoma. Nat Rev Clin Oncol. 2016;13(11):652.

44. A Phase III, Open-label, Multicenter Trial of Avelumab (MSB0010718C) Versus Platinum-based Doublet as a First-line Treatment of Recurrent or Stage IV PD-L1+ Non-small Cell Lung Cancer. ClinicalTrials.gov. Identifier: NCT02576574

45. Roach C, Zhang N, Corigliano E, Jansson M, Toland G, Ponto G, et al. Development of a companion diagnostic PD-L1 immunohistochemistry assay for pembrolizumab therapy in Non-small-cell lung cancer. Appl Immunohistochem Mol Morphol. 2016;24:392-7.

46. Phillips T, Simmons P, Inzunza HD, Cogswell J, Novotny Jr J, Taylor C, et al. Development of an automated PD-L1 immunohistochemistry (IHC) assay for non-small cell lung cancer. Appl Immunohistochem Mol Morphol. 2015;23(8):541-9.

47. Rebelatto MC, Midha A, Mistry A, Sabalos C, Schechter N, Li X, et al. Development of a programmed cell death ligand-1 immunohistochemical assay validated for analysis of non-small cell lung cancer and head and neck squamous cell carcinoma. Diagn Pathol. 2016;11:95.

48. McLaughlin J, Han G, Schalper KA, Carvajal-Hausdorf D, Pelekanou V, Rehman J, et al. Quantitative assessment of the heterogeneity of PD-L1 expression in non-small-cell lung cancer. JAMA Oncol. 2016;1:46-54.

49. Rizvi NA, Hellmann MD, Snyder A, Kvistborg P, Makarov V, Havel JJ, et al. Cancer immunology: mutational landscape determines sensitivity to PD-1 blockade in non-small cell lung cancer. Science. 2015;348(6230):124-8.

50. Taube JM, Klein A, Brahmer JR, Xu H, Pan X, Kim JH, et al. Association of PD-1, PD-1 ligands, and other features of the tumor immune micro-environment with response to anti-PD-1 therapy. Clin Cancer Res. 2014;20(19):5064-74.

51. Zaretsky JM, Garcia-Diaz A, Shin DS, Escuin-Ordinas H, Hugo W, HuLieskovan S, et al. Mutations associated with acquired resistance to PD-1 blockade in melanoma. N Engl J Med. 2016:375(9):819-29.

52. Kowanetz M, Koeppen H, Boe M, Chaft JE, Rudin CM, Zou W, et al. Spatiotemporal effects on programmed death ligand 1 (PD-L1) expression and immunophenotype of non-small cell lung cancer (NSCLC). J Thorac Oncol. 2015;10:9.

53. Johnson DB, Pectasides E, Feld E, Ye F, Zhao S, Johnpulle R, et al. Sequencing treatment in BRAFV600 mutant melanoma: anti-PD-1 before and after BRAF inhibition. J Immunother. 2017;40(1):31-5 [ABSTRACT].

54. Massi D, Brusa D, Merelli B, Falcone C, Xue G, Carobbio A, et al. The status of PD-L1 and tumor-infiltrating immune cells predict resistance and poor prognosis in BRAFi-treated melanoma patients harboring mutant BRAFV600. Ann Oncol. 2015;26(9):1980-7.

55. Rivalland G, Mitchell P. Combined BRAF and MEK inhibition in BRAF-mutant NSCLC. Lancet Oncol. 2016;17(7):860-2. doi:10.1016/S1470-2045(16)30203-0. Epub 2016 Jun 6.

56. Roskoski R. Allosteric MEK1/2 inhibitors including cobimetanib and trametinib in the treatment of cutaneous melanomas. Pharmacol Res. 2017:117:20-31

57. Ota K, Azuma K, Kawahara A, Hattori S, Iwama E, Tanizaki J, et al. Induction of PD-L1 expression by the EML4-ALK oncoprotein and downstream signaling pathways in non-small cell lung cancer. Clin Cancer Res. 2015;21:4014-21.

58. Chen N, Fang W, Zhan J, Hong S, Tang Y, Kang S, et al. Upregulation of PDL1 by EGFR activation mediates the immune escape of EGFR-Driven NSCLC: implications of optional immune targeted therapy for NSCLC patients with EGFR mutation. J Thorac Oncol. 2015;10:910-23.

59. Tang $Y$, Fang $W$, Zhang $Y$, Hong S, Kang $S$, Yan $Y$, et al. The association between PD-L1 and EGFR status and the prognostic value of PD-L1 in 
advanced non-small cell lung cancer patients treated with EGFR-TKIs. Oncotoarget. 2015;6:14209-19.

60. Lin C, Chen X, Li M, Liu J, Qi X, Yang W, et al. Programmed death-ligand 1 expression predicts tyrosine kinase inhibitor response and better prognosis in a cohort of patients with epidermal growth factor receptor mutationpositive lung adenocarcinoma. Clin Lung Cancer. 2015;16:e25-35.

61. Calles A, Liao X, Sholl LM, Rodig SJ, Freeman GJ, Butaney M, et al. Expression of PD-1 and its ligands, PD-L1 and PD-L2, in smokers and never smokers with KRAS mutant lung cancer. J Thorac Oncol. 2015;10:1726-35.

62. Barsoum IB, Smallwood CA, Siemens DR, Graham CH. A mechanism of hypoxia-mediated escape from adaptive immunity in cancer cells. Cancer Res. 2014;74:665-74

63. Hato SV, Khong A, De Vires IJ, Lesterhius WJ. Molecular Pathways: the immunogenic effects of platinum-based chemotherapeutics. Clin Cancer Res. 2014;20:2831-7.

64. Gajewski TF, Meng Y, Harlin H. Immune suppression in the tumor microenvironment. J Immunother. 2006;29:233-40.

65. Kline J, Brown IE, Zha YY, Blank C, Strickler J, Wouters H, Zhang L, Gajewski TF. Homeo-static proliferation plus regulatory T-cell depletion promotes potent rejection of B16 melanoma. Clin Cancer Res. 2008;14:3156-67.

66. Uyttenhove C, Pilotte L, Théate I, Stroobant V, Colau D, Parmentier N, Boon $\mathrm{T}$, Van den Eynde BJ. Evidence for a tumoral immune resistance mechanism based on tryptophan degradation by indoleamine 2,3-dioxygenase. Nat Med. 2003;9:1269-74.

67. Chen Y-b, Chuan-Yong M, Huang J-A. Clinical significance of programmed death-1 ligand-1 expression in patients with non-small cell lung cancer: a 5-year-follow-up study. Tumori. 2012;2012(6):751-5.

68. Illie M, Long-Mira E, Bence C, Butori C, Lassalle S, Bouhlel L, et al. Comparative study of the PD-L1 status between surgically resected specimens and matched biopsies of NSCLC patients reveal major discordances: a potential issue for anti-PD-L1 therapeutic strategies. Ann Oncol. 2016;27:147-53.

69. Food US, Administration D. Public workshop_complexities in personalized medicine: harmonizing companion diagnostics across a class of targeted therapies. March. 2015;24.

70. Fitzgibbons PL, Bradley LA, Fatheree LA, Alsabeh R, Fulton RS, Goldsmith JD, et al. Principles of analytic validation of immunohistochemical assays: guideline from the College of American Pathologists Pathology and Laboratory Quality Center. Arch Pathol Lab Med. 2014;138(11):1432-43.

71. Carvajal-Hausdorf DE, Schalper KA, Neumeister VM, Rimm DL. Quantitative measurement of cancer tissue biomarkers in the lab and in the clinic. Lab Invest. 2015;95(4):385-96.

72. Hirsch FR, McElhinny A, Stanforth D, Ranger-Moore J, Jansson M, Kulangara K. PD-L1 immunohistochemistry assays for lung cancer: results from phase 1 of the blueprint PD-L1 IHC assay comparison project. J Thorac Oncol. 2017;12(2):208-22. doi:10.1016/j.jtho.2016.11.2228. Epub 2016 Nov 29.

73. Higgs BW, Robbins PB, Blake-Haskins JA, Zhu W, Morehouse C, Brohawn PZ, et al. High tumoral IFN mRNA, PD-L1 protein, and combined IFNg mRNA/PD-L1 protein expression associates with response to durvalumab (anti-PD-L1) monotherapy in NSCLC patients. Eur J Cancer. 2015;51 suppl 3:S717, 15LBA.

\section{Submit your next manuscript to BioMed Central and we will help you at every step:}

- We accept pre-submission inquiries

- Our selector tool helps you to find the most relevant journal

- We provide round the clock customer support

- Convenient online submission

- Thorough peer review

- Inclusion in PubMed and all major indexing services

- Maximum visibility for your research

Submit your manuscript at www.biomedcentral.com/submit

) Biomed Central 